\title{
Leucine Binding Protein and Regulation of Transport in E. coli
}

\author{
Dale L. Oxender, James J. Anderson, Mary M. Mayo, and Steven C. Quay \\ Department of Biological Chemistry, University of Michigan, Ann Arbor, Michigan \\ 48109
}

Leucine is transported into E. coli cells by high-affinity transport systems (LIV-I and leucine-specific systems) which are sensitive to osmotic shock and require periplasmic binding proteins. In addition leucine is transported by a low-affinity system (LIV-II) which is membrane bound and retained in membrane vesicle preparations. The LIV-I system serves for threonine and alanine in addition to the 3 branched-chain amino acids. The LIV-II system is more specific for leucine, isoleucine, and valine while the high-affinity leucine-specific system has the greatest specificity.

A regulatory locus, liv $R$ at minute 22 on the E. coli chromosome produces negatively regulated leucine transport and synthesis of the binding proteins. Valineresistant strains have been selected to screen for transport mutants. High-affinity leucine transport mutants that have been identified include a LIV-binding protein mutant, $l i v J$, a leucine-specific binding protein mutant $l i v K$ and a nonbinding protein component of the LIV-I system, liv H. A fourth mutant, liv $P$, appears to be required only for the low-affinity LIV-II system. The existence of this latter mutant indicates that LIV-I and LIV-II are parallel transport systems. The 4 mutations concerned with high-affinity leucine transport form a closely linked cluster of genes on the E. coli chromosome at minute 74 .

The results of recent studies on the regulation of the high-affinity transport systems suggests that an attenuator site may be operative in its regulation. This complex regulation appears to require a modified leucyl-tRNA along with the transcription termination factor rho. Regulation of leucine transport is also defective in relaxed strains.

Among the branched-chain amino acids only leucine produces regulatory changes in LIV-I activity suggesting a special role of this amino acid in the physiology of $\mathrm{E}$. coli. It was shown that the rapid exchange of external leucine for intracellular isoleucine via the LIV-I system could create an isoleucine pseudoauxotrophy and account for the leucine sensitivity of E. coli.

Key words: regulation, amino acid transport, mutants, leucine sensitivity, leucine, isoleucine, valine

E. coli have developed 2 basic types of active transport systems for leucine. One of these transport systems is a low-affinity membrane-bound system (LIV-II) and can be observed in membrane vesicle preparations described by Kaback (1). High-affinity trans. 


\section{0:JSS Oxender et al.}

port systems for leucine (LIV-I and leucine-specific) in E. coli are sensitive to osmotic shock (2) and require periplasmic binding proteins. The leucine binding proteins have been described in various review articles (3-5). The high-affinity LIV-I system has a $K_{m}$ for leucine of $10^{-7} \mathrm{M}$ and also transports isoleucine, valine, threonine, and alanine. The leucine-specific system comprises about $20 \%$ of the high-affinity transport capacity for leucine of wild-type E. coli K-12. The regulation of the high-affinity transport systems which respond to the level of leucine in the medium has been extensively studied in our laboratory $(6-10)$. Mutations resulting in a loss of leucine repression have been mapped and characterized $(6,10)$. The mutations $l i v R$ (signifying a derepression of the LIV-I and leucine-specific systems) and $l s t R$ (signifying derepression of the leucine-specific system and the LIV-II systems) determine negatively acting regulatory elements and are genetically closely linked. Our current understanding of the regulation of leucine transport suggests that leucine interacts with tRNAleu and the leucyl-tRNA synthetase to produce this regulation. The regulation primarily changes the differential rate of synthesis of transport components relative to total cellular proteins (9). We have recently shown that mutations that alter the hisT gene which codes for a tRNA modifying enzyme (11) and the rho allele which codes for a transcription termination factor (12) also produce a derepression of leucine transport $(13,14)$. These results suggested that an "attenuator" type of regulation obtains similar to that described for the regulation of tryptophan (15), histidine (16), and branchedchain amino acid (11) biosynthetic pathway enzymes.

Analysis of the structural components of the high-affinity and low-affinity transport systems for leucine has been aided by our recent identification (17) of a genetic complex which codes for at least 4 functions involved in binding protein expression and LIV-II transport expression. This complex is linked to malT on the E. coli genetic map, approximately $180^{\circ}$ from the regulatory loci liv $R$ and $l s t R$.

\section{METHODS}

\section{Growth Conditions}

Growth supplements for auxotrophic strains when not indicated otherwise were: $50 \mu \mathrm{g} / \mathrm{ml}$ for all L-amino acids except for L-leucine which was used at a concentration of $25 \mu \mathrm{g} / \mathrm{ml}$; thymine $50 \mu \mathrm{g} / \mathrm{ml}$; vitamins $1 \mu \mathrm{g} / \mathrm{ml}$, glucose $0.2 \%$.

For all experiments the medium consisted of a morpholino propane sulfonatebuffered salts solution (MOPS) described by Neidhardt et al. (18). All supplements were either sterilized by filtration through $0.2 \mu \mathrm{m}$ membrane filters or autoclaved.

Cultures were grown aerobically in 125 - or 250 -ml erlenmeyer flasks in a shaking water bath (New Brunswick Scientific Company, Model G-76) that maintained constant temperatures between 30 and $41 \pm 0.25^{\circ} \mathrm{C}$. The platform rotation was approximately $150 \mathrm{rpm}$. Cell growth was followed by monitoring absorbance at $420 \mathrm{~nm}$ at room temperature using a GCA-McPherson model EU 707-12 spectrophotometer.

\section{Isolation of Binding Protein}

Binding protein was isolated by the osmotic shock procedure and binding activity determined by equilibrium dialysis as described previously (5).

\section{Transport Assays}

Routine transport assays, as well as the rapid transport assay variant for screening large number of prospective transport mutants, were performed as described previously (10). 


\section{Enzymes Assays}

The following enzymes were assayed as referenced:

Threonine deaminase: (E. C. 4.2.1.6; L-threonine hydrolyase [deaminating] : (threonine dehydratase) (19) except that the absorbance of the 2,4-dinitrophenylhydrazone derivative of $\alpha$-ketobutyrate was measured at $530 \mathrm{~nm}$ in a Zeiss PMQ2 spectrophotometer.

Acetohydroxy acid synthetase: (AHAS; acetolactate synthetase, E.C.4.1.3.18) (20) 3-isopropylmalate dehydrogenase (IPMP; 2 -hydroxy-4-methyl-3-carboxyvaleratenicotinamide adenine dinucleotide oxidoreductase. E. C. 1.1.1.85) (21).

\section{Mu Phage Procedure}

Wild type Mu-1 and Mucts 62 lysates were prepared as already described (17).

\section{Mu Mutagenesis}

E. coli cultures were grown to a density of $2 \times 10^{8}$ cells $/ \mathrm{ml}$ in LBT broth supplemented with $0.01 \mathrm{M} \mathrm{MgSO}_{4}$ and mutagenized by adding $\mathrm{Mu}$ or Mucts phage to a multiplicity of infection of 1.0 . After lysis at the appropriate temperature $\left(37^{\circ} \mathrm{C}\right.$ for $\mathrm{Mu}, 30^{\circ} \mathrm{C}$ for Mucts) the cultures were allowed to grow overnight. Procedures for detecting Mu lysogeny have been previously described (17).

\section{SDS-Polyacrylamide Gel Electrophoresis}

Slab gels containing $11 \%$ acrylamide and $0.1 \%$ SDS (sodium dodecyl sulfate) were prepared by the method of Laemmli (22). The gels were $1.5 \mathrm{~mm}$ thick. Samples of concentrated shock fluids were prepared in $1 \%$ SDS by heating for 2 min at $100^{\circ} \mathrm{C}$. After electrophoresis the gels were fixed, stained, and destained by the method of Fairbanks (23). The gels were dried on filter paper under vacuum and photographed.

\section{RESULTS}

\section{Isolation of Mutants in the Branched-Chain Amino Acid Uptake Systems}

Regulatory mutants. Among spontaneous mutants selected for the ability to grow on D-leucine were mutants with elevated levels of branched-chain amino acid transport (6). The mutant allele $l i v R$ results in failure of L-leucine to repress the osmotic shock-sensitive high-affinity LIV-I and leucine-specific transport systems and their respective binding proteins, but has no apparent effect on the membrane-bound low-affinity LIV-II system $(6,10)$. The $l s t R$ allele, However, results primarily in a derepression of the leucine-specific transport system and in the level of leucine-specific binding protein, with an apparent twofold increase in the LIV-II system as well (10 and unpublished experiments). The IstR mutation permits the cells to utilize lower levels of D-leucine than the liv $R$ mutation (Table I). Since these 2 distinct patterns of regulation suggested that different functions were specified by the $l i v R$ and $l s t R$ alleles, a complementation test was carried out between $l s t R$ and $l i v R$ mutants. Strains were constructed which were diploid for the E. coli chromosome covering the region in which $l s t R$ and liv $R$ are located (Fig. 1). Previous work had indicated very close linkage between these 2 alleles (10). Both $l s t R$ and livR are recessive to their respective wild-type alleles (Table II, strains 1,2,3, and 5) which therefore indicates that they produce a negatively operating, diffusable factor. The merodiploid strain listed as number 4 in Table II is homozygous for 1 st $R$ and displays the mutant phenotype. Strains homozygous for liv $R$ also display the mutant phenotype (10). Strain number 6 , however, shows that the wild-type alleles of livR and $l s t R$ can complement 
TABLE I. Growth Phenotypes of liv Mutants

\begin{tabular}{|c|c|c|c|c|}
\hline \multirow[b]{2}{*}{ Mutation ${ }^{a}$} & \multicolumn{4}{|c|}{ Colony formation ${ }^{d}$ on medium supplemented with } \\
\hline & $0.03 \mu \mathrm{M}$ L-leucine $\mathrm{b}^{\mathrm{b}}$ & $0.4 \mu \mathrm{M}$ L-valine ${ }^{\mathrm{c}}$ & $850 \mu \mathrm{M}$ D-leucine ${ }^{\mathrm{b}}$ & $1,700 \mu \mathrm{M}$ D-leucine $\mathrm{b}^{\mathrm{b}}$ \\
\hline $\operatorname{liv}^{+}$ & + & + & - & - \\
\hline $\operatorname{liv} R$ & + & - & - & + \\
\hline $1 s t R$ & + & - & + & + \\
\hline $\operatorname{liv} R \operatorname{liv} J$ & + & + & - & + \\
\hline $\operatorname{liv} R \operatorname{liv} K$ & + & + & - & - \\
\hline $\operatorname{liv} R \operatorname{liv} H$ & + & + & - & - \\
\hline lst $R$ livH livP & - & + & - & - \\
\hline
\end{tabular}

${ }^{\mathrm{a}}$ Complete strain descriptions are published elsewhere; all strains are isogenic and carry the derepressed transport allele liv $R(10)$ except livH livP, which is in a lst $R$ strain background.

$b_{\text {Determined in leu strain background }}$

${ }^{c}$ Determined in $l e u^{+}$strain background

$\mathrm{d}_{\text {Determined after }} 72-\mathrm{h}$ incubation at $32^{\circ} \mathrm{C}$

TABLE II. Complementation Analysis of $l s t R$ and livR Alleles in F-prime Merogenotes

\begin{tabular}{|c|c|c|c|}
\hline \multicolumn{4}{|c|}{ Phenotype } \\
\hline \multicolumn{2}{|c|}{ Merogenote genotype $\mathrm{a}^{\mathrm{a}}$} & L-leucine uptake, $\mathrm{nmol} / \mathrm{min} / \mathrm{mg}$ dry wt. & $\begin{array}{l}\text { Colony formation, } \\
1,700 \mu \mathrm{M} \text { D-leucine }\end{array}$ \\
\hline \multirow{2}{*}{ 1. $\frac{F}{-}$} & + & \multirow{2}{*}{0.020} & \multirow{2}{*}{-} \\
\hline & $+\quad+$ & & \\
\hline \multirow{2}{*}{ 2. $F$} & + & \multirow{2}{*}{0.012} & \multirow{2}{*}{-} \\
\hline & $\operatorname{livR}$ & & \\
\hline \multirow{2}{*}{ 3. $\mathrm{F}$} & + & \multirow{2}{*}{0.020} & \multirow{2}{*}{-} \\
\hline & $+\quad l s t R$ & & \\
\hline \multirow{2}{*}{ 4. $\stackrel{F}{-}$} & $+\quad l s t R$ & \multirow{2}{*}{0.052} & \multirow{2}{*}{+} \\
\hline & $+\quad l s t R$ & & \\
\hline \multirow{2}{*}{ 5. $\mathrm{F}$} & $+\quad l s t R$ & \multirow{2}{*}{0.03} & \multirow{2}{*}{ - } \\
\hline & + & & \\
\hline \multirow{2}{*}{6.} & $+\quad l s t R$ & \multirow{2}{*}{0.018} & \multirow{2}{*}{-} \\
\hline & $\operatorname{liv} R \quad+$ & & \\
\hline
\end{tabular}

astrains carrying the $\mathrm{F} 147 \mathrm{gal}^{+} \mathrm{F}$-prime (35) were constructed from recipients which were, in addition to the designated transport alleles, $r e c A$ gal leu. They were grown on galactose minimal medium supplemented with $25 \mu \mathrm{g} \mathrm{L}$-leucine per $\mathrm{ml}$. The F $147 \mathrm{ts} t R$ episome was isolated from a D-leucine utilizing homogenote of a recA ${ }^{+}$strain similar in genotype to strain No. 3, above.

each other, yielding the wild-type phenotype. We conclude from these results that livR and $l s t R$ are separate genes, each controlling a different pattern of regulation of the branched-chain amino acid uptake systems. The molecular nature of these gene products is under investigation. 


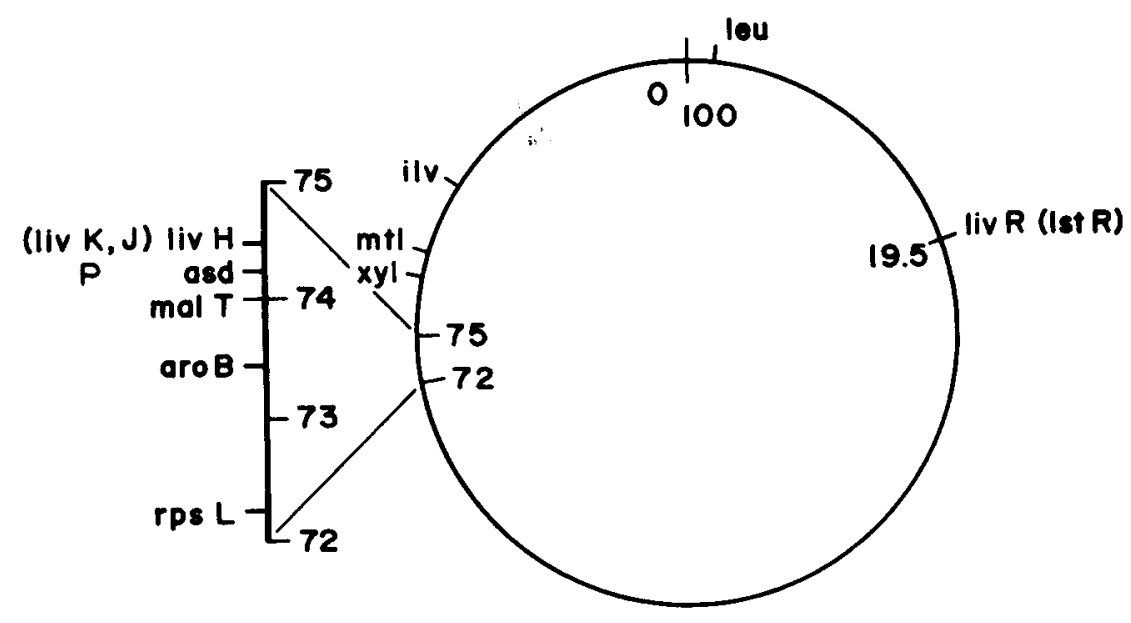

Fig. 1. Simplified genetic map of the E. coli chromosome taken from Bachman, Low, and Taylor (24) showing positions of liv mutations discussed within. Alleles in parentheses have not been precisely mapped.

\section{Isolation of Mutants Defective in Branched-Chain Amino Acid Uptake Systems}

Mutant strains possessing the livR allele have increased sensitivity to L-valine, which inhibits the growth of E. coli K-12 (Table I). Mutations to $L$-valine resistance were induced by the mutator phage $\mathrm{Mu}$ in strains possessing the livR allele (Table I). A concentration of L-valine was chosen which would prevent colony formation only in strains with elevated levels of the LIV-I system in order to avoid excessive selective pressure (17). Three biochemically distinct classes of mutants were found which have been designated livH, livJ, and livK (17). These map together by transduction and are closely linked to malT (17 and Fig. 1). The transport of L-leucine in these strains has been diminished (Table III) without affecting the transport of other amino acids (17). The mutation livK results in a loss of all detectable high-affinity leucine uptake (LIV-I and leucine-specific systems) and a loss of the leucine-specific binding protein, both by in vitro activity (Table I) and by SDSpolyacrylamide gel electrophoresis (Fig. 2). The LIV-binding protein is still present in these strains even though all high-affinity transport is lost. The high-affinity uptake of L-valine and L-isoleucine has also been eliminated (17), as has the ability of the cells to utilize D-leucine (Table 1). The liv $J$ mutation eliminates the LIV-I high-affinity uptake but the leucine-specific system and LIV-II system are unaffected. There is a parallel loss of the LIV-binding protein activity and the corresponding band on SDS-polyacrylamide gel slabs (Table III and Fig. 2). D-Leucine utilization, however, is retained (Table I) indicating that the D-leucine utilization phenotype in liv $R$ and $l s t R$ strains is presumably due to a derepression of the leucine-specific system. The mutation liv $H$ eliminates both high-affinity transport systems without producing any detectable change in the mobilities or activities (Table III, Fig. 2 and Ref. 17) of the 2 binding proteins. Evidently liv $H$ codes for an additional factor of high-affinity uptake, at present unidentified. 
TABLE 11I. Transport Phenotypes of liv Mutants

\begin{tabular}{|c|c|c|c|c|c|c|}
\hline \multirow[b]{2}{*}{ Mutation ${ }^{a}$} & \multirow{2}{*}{$\begin{array}{c}\text { Percent of wild-type } \\
\text { leucine uptake }\end{array}$} & \multicolumn{3}{|c|}{ L-leucine uptake systems } & \multicolumn{2}{|r|}{$\begin{array}{l}\text { L-leucine-binding } \\
\text { protein activity }\end{array}$} \\
\hline & & LIV-I & Leucine-specific & LIV-II & LIV & Leucine-specific \\
\hline $\mathrm{liv}^{+}$ & 100 & + & + & + & + & + \\
\hline $\operatorname{liv} K$ & 10 & - & - & + & + & - \\
\hline $\operatorname{liv} J$ & 55 & - & + & + & - & + \\
\hline $\operatorname{liv} H$ & 15 & - & - & + & + & + \\
\hline $\operatorname{liv} H \operatorname{liv} P$ & 2 & - & - & - & + & + \\
\hline
\end{tabular}

astrains, same as Table I

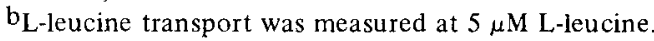

CThe leucine-specific and LIV-I systems are defined by their low $\mathrm{K}_{\mathrm{m}}(0.1-0.4 \mu \mathrm{M})$ for L-leucine; the leucine-specific system resists inhibition by $\mathrm{L}$-isoleucine and is responsible for $\mathrm{D}$-leucine uptake. The LIV-II system has a higher $\mathrm{K}_{\mathrm{m}}(2-4 \mu \mathrm{M})$ for L-leucine and also transports L-isoleucine and L-valine. Presence or absence of a given system was determined by kinetic analysis over substrate ranges from $0.02 \mu \mathrm{M}$ to $20 \mu \mathrm{M}(6)$.

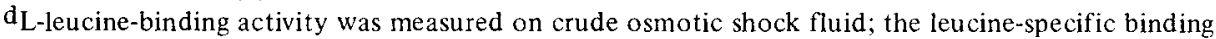
protein activity was determined by resistance of L-leucine binding to L-isoleucine competition ( 10 ).

A third group of mutants were obtained which were defective in the low-affinity (LIV-II) transport system. These mutants were obtained by inducing a second mutation in the livH mutant strain by mutagenizing the liv $H$ strain with ethyl methane sulfonate and penicillin-enriching for mutant strains unable to utilize low concentrations of L-leucine (Table I). One of these mutations has been designated liv $P$. Conjugational analysis has shown that $l i v P$ is also linked to malT (unpublished observations, Fig. 1). Transport of L-leucine in the double mutant livH liv $P$ has been dramatically lowered over that of the parent $l i v H$ strain (Table III), and kinetic analysis (data not shown) has revealed that the LIV-II system has been reduced to undetectable levels. Thus, in this double mutant strain both high-and low-affinity transport systems for leucine have been mutationally eliminated. Other workers, however $(25,26)$ have reported additional low-affinity uptake systems for leucine. We are presently characterizing the remaining leucine uptake in the double mutant strain to ascertain the nature of the residual leucine uptake.

A genetic complex is suggested for leucine transport genes in E. coli by these studies since at least 4 different genes specifying components of the known transport systems for leucine map in the same region. We believe that the structural genes for the leucine-binding proteins are part of this complex since a previously reported mutation altering the structure of the leucine-specific binding protein (6) also maps in this area (17). We are presently characterizing other mutants by complementation analysis and fine mapping to better define the genetic organization of the region. We are also attempting to biochemically identify the components coded for by the $l i v H$ and liv $P$ genes.

\section{Regulation of Leucine Transport}

Repression by leucine. Early studies showed that high-affinity leucine transport activity is highly regulated and responds to the level of leucine in the growth medium (6). There is a direct relationship between the level of high-affinity leucine transport and the 


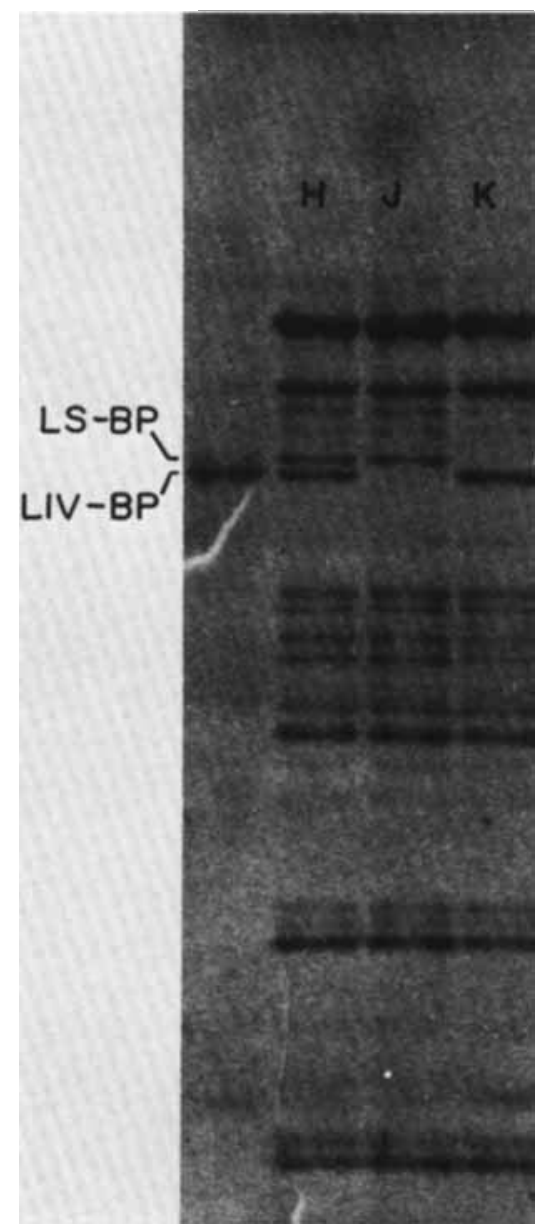

Fig. 2. Sodium dodecyl sulfate-polyacrylamide gel profile of crude osmotic shock fluid proteins. The slab gels were prepared according to the method of Laemmli (22) and were $11 \%$ acrylamide. Direction of migration is from top to bottom. A sample of pure LIV-binding protein (LIV-BP) and a trace of the leucine-specific binding protein (LS-BP) are shown on the left; $\mathrm{H}$ ) shock fluid from a strain carrying the liv $H$ mutation, J) strain with liv $J$ mutation, and $\mathrm{K}$ ) strain with livH. The wild-ty pe profile (not shown) is identical to $\mathrm{H}$.

level of the leucine-binding proteins (17). The correlation between the transport capacity and the amount of binding protein shows that the binding proteins are the rate limiting component in the transport of leucine into $\mathrm{E}$. coli. When $\mathrm{E}$. coli is grown on nutrient medium or minimal medium containing $25-50 \mu \mathrm{g} / \mathrm{ml} \mathrm{L-leucine} \mathrm{essentially} \mathrm{complete} \mathrm{re-}$ pression of the synthesis of both the LIV and the leucine-specific binding proteins occurs and essentially all high-affinity leucine transport is abolished (27). 


\section{Separate Regulation of Biosynthesis and Transport of Leucine}

The levels of the leucine biosynthetic enzymes are also regulated by the intracellular level of branched-chain amino acids (28). Since both transport and biosynthetic enzymes for leucine were repressed by growth on leucine we attempted to determine whether these 2 processes were regulated in a concerted manner. For these studies we collaborated with Dr. Umbarger of Purdue University. We provided Dr. Umbarger with mutant strains that were derepressed for leucine transport and he gave us several mutants that were derepressed for the biosynthetic enzymes of the branched-chain pathway. We examined the regulation of leucine transport in strains that were derepressed for biosynthesis (leuABCD, $i l v B, i l v A D E$ ) as well as a deletion of the entire leucine biosynthetic operon. Leucine transport activities and leucine-binding protein levels in these strains were regulated in a normal manner. Using the transport mutants from our laboratory, Dr. Umbarger showed that the regulation of the biosynthetic enzymes for the branched-chain amino acids was not altered in mutants with derepressed transport and leucine-binding proteins. The normal regulation of transport in E. coli strains with deletions of the entire biosynthetic operon indicated that none of the gene products of this operon are required for regulation of transport. We concluded from these studies that the transport systems and the biosynthetic enzymes in E. coli are not regulated together by a cis-dominant type of mechanism and although both systems appear to have components in common it is possible to obtain separate regulatory mutations for each system $(7,13)$.

\section{Role of Leucyl tRNA Synthetase in Transport Regulation}

A possible candidate for a common component in the regulation of both transport and biosynthesis of leucine is the requirement for aminoacyl tRNA rather than the free leucine. Extensive studies in other laboratories have indicated aminoacyl-tRNA synthetases are part of the regulatory system for branched-chain amino acid biosynthesis (29). The availability of temperature-sensitive mutants for the leucyl-tRNA synthetase (leuS1) permitted us to determine whether this enzyme was also involved in the regulation of the transport of leucine. We examined both the level of transport activity and the level of the periplasmic-binding proteins in the temperature-sensitive mutant strain (leuS1) grown at the permissive temperature $\left(36^{\circ} \mathrm{C}\right)$ and the nonpermissive temperature $\left(41^{\circ} \mathrm{C}\right)$. Strain EB143 has a complete deletion of the leucine biosynthetic operon which avoids the increased endogenous levels of leucine that would be produced in a prototrophic temperature sensitive leuS strain grown at $41^{\circ} \mathrm{C}$. Strain EB1 44 served as the isogenic non-temperaturesensitive control strain. The results are presented in Table IV. When mutant strain EB143 was shifted from 36 to $41^{\circ} \mathrm{C}$ the transport activity for leucine, isoleucine, and valine was greatly increased. Little effect was observed for proline or histidine uptake. Proline is transported by a membrane-bound transport system that derives its energy from the membrane potential while histidine is transported by a periplasmic-binding protein system and derives its energy more directly from ATP. The derepression of threonine deaminase that was observed for strain EB143 when it was shifted to $41^{\circ} \mathrm{C}$ was the expected response of a branched-chain amino acid biosynthetic enzyme which is subject to multivalent repression. The branched-chain amino acid transport system responds only to changes in the leucine level. Isoleucine and valine $t R N A$ synthetase mutants did not produce regulatory changes in the transport activity. The shock fluid of strains EB143 and EB144 were examined for leucine-binding proteins when the cells were grown at $41^{\circ} \mathrm{C}$. There is a fivefold derepression in the synthesis of the binding proteins for leucine when the temperature is shifted to $41^{\circ} \mathrm{C}$ 
TABLE IV. Expression of Transport and a Biosynthetic Enzyme Activity in Strains EB143 and EB144

\begin{tabular}{|c|c|c|c|c|c|}
\hline \multirow[b]{2}{*}{ Strain } & \multirow{2}{*}{$\begin{array}{l}\text { Growth } \\
\text { conditions }\end{array}$} & \multicolumn{3}{|c|}{ Transport activities $b$} & \multirow{2}{*}{$\begin{array}{l}\text { Threonine } \\
\text { deaminase }\end{array}$} \\
\hline & & Leu & Ile & $\mathrm{Val}$ & \\
\hline EB 143, ara-leu $\triangle 1101$, leuS1 & $36^{\circ} \mathrm{C}$ & 100 & 65 & 87 & 26 \\
\hline EB144, ara-leu $\triangle 1101$ & $36^{\circ} \mathrm{C}$ & 87 & 61 & 70 & 16 \\
\hline E.B 143 , ara-leu $\triangle 1101$ leuSl & $41^{\circ} \mathrm{C}$ & 470 & 773 & 904 & 450 \\
\hline $\mathrm{EB} 144$, ara-leu $\triangle 1101$ & $41^{\circ} \mathrm{C}$ & 96 & 70 & 74 & 41 \\
\hline
\end{tabular}

aGrowth in glucose-basal salts medium plus $0.2 \mathrm{mM}$ L-leucine.

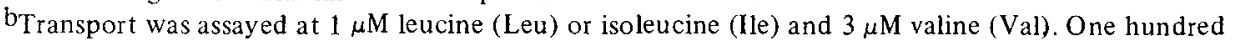
percent represents $0.23 \mathrm{mmol}$ leucine taken up per min per $\mathrm{kg}$ cells dry weight.

eSpecific activity represents $\mu$ mol of $\alpha$-ketobutyrate formed per min/g of cellular protein. The growth media included $0.4 \mathrm{mM} \mathrm{L-leucine} \mathrm{and} \mathrm{L-isoleucine} \mathrm{and} 1 \mathrm{mM} \mathrm{L}$-valine.

with little change in the control strain. These results were consistent with a role of the binding proteins in the rate limiting step in leucine transport and further indicated that the synthesis of the binding proteins is regulated by the level of modified leucyl-tRNA or the leucyl-tRNA synthetase. We obtained a mutant strain with a defect in the maturation of leucyl-tRNA to distinguish between these 2 alternatives.

\section{Role of hisT Gene Product}

The hisT locus codes for an enzyme that converts uridine to pseudouridine in the tRNAs for leucine, histidine, and tyrosine. The regulation of biosynthetic enzymes for these 3 amino acids is no longer sensitive to their cognate amino acids in strains containing a hisT mutation (11). We obtained E. coli strains containing a hisT mutation from Drs. R. P. Lawther and W. Hatfield. An examination of leucine transport activity in the hisT strain showed that the regulation was abnormal. The hisT strain showed a higher transport of leucine than the parental strain when grown under repressing conditions and furthermore it failed to derepress leucine transport activity when grown under conditions of leucine limitation. Under these same conditions the biosynthetic pathway for leucine also does not show a repression or derepression regulation (Quay SC, unpublished observations). We reported similar results for a role of the his $T$ gene product in the regulation of leucine transport activity in Salmonella typhimurium (13). The results of these 2 studies with $h i s T$ strains provide evidence that the repression of transport of leucine requires fully maturated tRNA which is aminoacylated with leucine.

\section{Role of rho in Transport Regulation}

Recent reports have shown that several of the biosynthetic operons in bacteria contain an "attenuator" site near the operator region that acts as a barrier to transcription by RNA polymerase $(15,16)$. The termination factor rho has been implicated in attenuator function. To test if transport for leucine, isoleucine, and valine is under an attenuator-type regulation 2 strains were obtained from Dr. Umbarger of Purdue University, which were leucine auxotrophs with one having a suA120 allele (14). The suA120 allele is a missense mutation in the rho factor (30). The initial rate of transport of 8 amino acids was measured in 
TABLE V. Effect of a Mutation in Termination Factor rho on Amino Acid Transport

\begin{tabular}{lcc}
\hline & \multicolumn{2}{c}{ Specific transport activity ( $\mu \mathrm{mol} / \mathrm{min} / \mathrm{g}$ cells, dry wt.) } \\
\cline { 2 - 3 } Substrate & $\begin{array}{c}\text { Control strain } \\
\text { CU300a }\end{array}$ & $\begin{array}{c}\text { SuA mutant } \\
\text { CU2054a }\end{array}$ \\
\hline Arginine $(3 \mu \mathrm{M})$ & 2.92 & 3.61 \\
Glutamine $(1 \mu \mathrm{M})$ & 1.90 & 0.63 \\
Histidine $(1 \mu \mathrm{M})$ & 0.20 & 0.38 \\
Isoleucine $(1 \mu \mathrm{M})$ & 0.12 & 0.24 \\
Leucine $(1 \mu \mathrm{M})$ & 0.10 & 0.19 \\
Proline $(3 \mu \mathrm{M})$ & 0.17 & 0.17 \\
Tryptophan $(3 \mu \mathrm{M})$ & 0.51 & 0.55 \\
Valine $(3 \mu \mathrm{M})$ & 0.31 & 0.61 \\
\hline
\end{tabular}

aCells were grown in MOPS-G, $0.2 \mathrm{mM}$ leucine, and $25 \mathrm{mg} /$ liter tryptophan. Cells were harvested and transport assayed as described previously (9).

the rho mutant and the isogenic parental strain. The data are presented in Table V. The uptake of leucine, isoleucine, and valine is increased twofold even though leucine is present in the growth medium. Arginine and histidine transport activity is also increased in the rho mutant. Tryptophan and proline uptake is unchanged but glutamine is greatly decreased. The kinetics of uptake showed that the $\mathrm{K}_{\mathrm{m}}$ values for both the high- and the lowaffinity transport systems for leucine in the rho mutant were similar to those obtained for the parental strain. The $V_{\max }$ value for the high-affinity leucine uptake was increased approximately eightfold in the rho mutant. The $\mathrm{V}_{\max }$ of the low-affinity system was only slightly elevated.

An examination of the leucine-binding activity in the osmotic shock fluid was carried out. The leucine-binding activity showed a fourfold increase in the rho mutant. In a similar manner the histidine- and arginine-binding activities in the osmotic shock fluid were increased somewhat while glutamine-binding activity decreased significantly. These results show that rho-dependent transcriptional termination is important for leucinespecific repression of branched-chain amino acid transport (14).

\section{Leucine Sensitivity}

The livR locus, which leads to a trans-recessive derepression of the high-affinity transport system for leucine is responsible for greatly increased sensitivity toward growth inhibition by leucine, valine, serine, and certain analogues such as 4-azaleucine or $5^{\prime}, 5^{\prime}, 5^{\prime}$-trifluoroleucine (31). We recently showed that the ability of the LIV-I transport system to carry out exchange of endogenous amino acids for extracellular leucine is a major factor in leucine sensitivity. When E. coli cells are shifted from nutrient medium to minimal medium containing leucine a long lag time in the resumption of growth is observed. The lag time in the growth represents the time required to derepress certain biosynthetic enzymes. Added isoleucine antagonizes the leucine sensitivity showing that the necessary derepression of the biosynthesis of isoleucine is prevented by leucine. We were able to show that the necessary biosynthetic enzymes for isoleucine cannot by synthesized. The high-affinity transport system serves for rapid exchange of branched-chain amino acids while the low-affinity system does not produce significant exchange of these amino acids. 
These results provide a mechanism for leucine sensitivity and explain the increased sensitivity of strains with derepressed high-affinity transport such as that shown by the liv $R$ mutant strain.

\section{DISCUSSION}

The results presented above describe the 2 types of active transport systems in E. coli for the branched-chain amino acids. One type is membrane bound and can be observed in membrane vesicles (LIV-II), and the other type is osmotic-shock sensitive and requires binding proteins to produce active transport of leucine (LIV-I). A regulatory genetic locus, liv $R$, at minute 22 on the E. coli chromosome produces negatively regulated leucine transport and synthesis of the leucine-binding proteins. Valine-resistant strains that were still sensitive to the dipeptide glycylvaline were selected as potential LIV-I transport mutants. Among the valine-resistant mutants we identified a LIV-binding protein mutant (livJ), a leucine-specific binding protein mutant (livK), and a nonbinding protein component of the LIV-I system (livH). A fourth mutation, livP, appears to be a component of the low-affinity LIV-II system. Since a liv $P$ mutant appears to have normal LIV-I transport we have concluded that the LIV-I and LIV-II systems represent parallel systems even though they may have certain components in common. These mutations concerned with leucine transport form a cluster closely linked to malT at minute 74 on the E. coli chromosome. The positions of these mutations are distinctly different from that of $b r n Q, b r n R$, and $b r n S$ mutations of branched-chain amino acid transport described by laccarino and co-workers (26).

Continued studies of the chemical and physical properties of the LIV-and leucinespecific binding proteins are being carried out in collaboration with other laboratories. Dr. Ovchinnikov and co-workers of Moscow, USSR, have recently published the complete amino acid sequence of the LIV-binding protein (32) and are currently sequencing the leucine-specific binding protein which is structurally very similar. Antonov et al. (33) have shown that a concentration-dependent reversible association of the LIV-binding protein may occur producing aggregates with an apparent molecular weight up to 300,000 . The presence of these aggregates has been correlated with nonlinear Scatchard plots of leucine-binding activity. Alternative explanations for nonlinear Scatchard plots of leucine binding to the LIV-binding protein have been offered by Anraku and co-workers (34). These studies suggest that binding protein preparations contain bound ligand which could alter the specific activity of added ligand at high protein to ligand ratios.

Figure 3 presents a scheme of the regulatory components of the LIV-I transport system which responds to the level of leucine added to the medium. Modified leucyl-tRNA appears to play a role in the regulation along with the transcription termination factor rho. The results of this study suggest an attenuator site may be operative in the regulation of high-affinity leucine transport. This complex regulatory system for transport of leucine is similar to that of its biosynthesis suggesting the important role of the LIV-I transport system to the physiology of the bacterial cell. Since changes in isoleucine or valine levels do not produce regulatory changes in LIV-I a special role of leucine in the physiology of E. coli is implied. The properties of the LIV-I system that give rise to a rapid exchange of leucine for isoleucine, thus creating isoleucine pseudoauxotrophy under certain conditions, have helped to explain the leucine sensitivity of E. coli (31). This complex regulatory system for the transport of leucine which is similar to that of the biosynthetic enzymes provides an example of the important role transport systems can play in amino acid metabolism. 


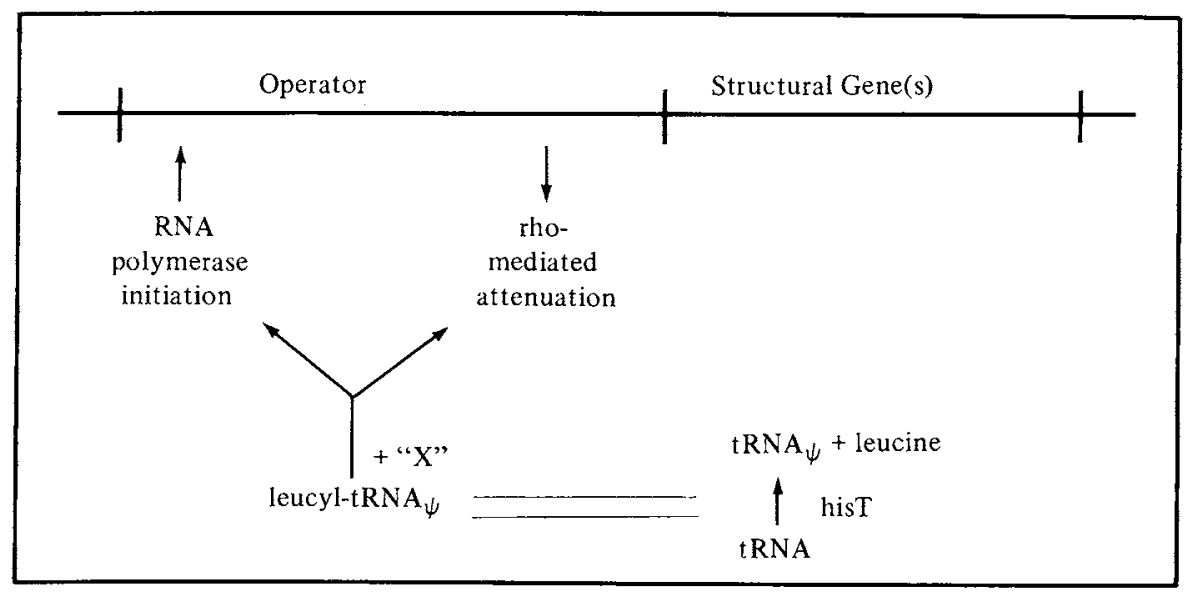

Fig. 3. Model of leucine transport regulation in E. coli.

\section{ACKNOWLEDGMENTS}

We wish to thank Dr. H. E. Umbarger of Purdue University and Drs. R. P. Lawther and $W$. Hatfield of The University of California at Irvine for the E. coli strains containing the hisT mutation. This investigation was supported by Public Health Service Grant GM1 1024 to D.L.O. from the National Institutes of General Medical Sciences.

\section{REFERENCES}

1. Kaback HR: Methods Enzymol 22:99, 1971.

2. Neu HC, Heppel LA: J Biol Chem 240:3685, 1965.

3. Oxender DL: Annu Rev Biochem 41:777, 1972.

4. Oxender DL: In Manson LA (ed): "Biomembranes" New York: Plenum Press, 1975, vol 5 p 25.

5. Oxender DL, Quay SC: In Korn ED (ed): "Methods of Membrane Biology." New York: Plenum Press, 1976, vol 6, p 183.

6. Rahmanian M, Claus DR, Oxender DL: J Bacteriol 1 16:258, 1973.

7. Quay SC, Oxender DL, Tsuyumu S, Umbarger HE: J Bacteriol 122:994, 1975.

8. Quay SC, Kline EL, Oxender DL: Proc Natl Acad Sci USA 72:3921, 1975.

9. Quay SC, Oxender DL: J Bacteriol 127:1225, 1976.

10. Anderson JJ, Quay SC, Oxender DL: J Bacteriol 126:80, 1976.

11. Cortese R, Landsberg RA, Vonder Haar RA, Umbarger HE, Ames BN: Proc Natl Acad Sci USA $71: 1857,1975$.

12. Beckwith J, Biochim Biophys Acta $76: 162,1963$.

13. Oxender DL, Quay SC: J Cell Physiol 89:517, 1976.

14. Quay SC, Oxender DL: J Bacteriol 130:1024, 1977.

15. Bertrand K, Korn L, Lee F, Platt T, Squires CL, Yanofsky C: Science 189:22, 1975.

16. Artz SW, Broach JR: Proc Natl Acad Sci USA 72:3453, 1975.

17. Anderson JJ, Oxender DL: J Bacteriol 130:384, 1977.

18. Neidhardt FC, Block PL, Smith DF: J Bacteriol 119:736, 1974.

19. Burns RO: In Tabor H, Tabor CW (eds): "Methods in Enzymology." New York: Academic Press, 1971, vol 17, part B, p 555. 
20. Stormer FC, Umbarger HE: Biochem Biophys Res Commun 17:587, 1974.

21. Burns RO, Umbarger HE, Gross SR: Biochemistry 2:1053, 1963.

22. Laemli VK: Nature (Iondon) 227:680, 1970.

23. Fairbanks G, Steck TL, Wallach DFH: Biochemistry 10:2606, 1971.

24. Bachman BJ, Low KB, Taylor AL: Bacteriol Rev 40:116, 1976.

25. Wood JM: J Biol Chem 250:4477, 1975.

26. Guardiola J, Iaccarino M: J Bacteriol 117:393, 1974.

27. Peurose WR, Nichoalds GE, Piperno JR, Oxender DL: J Biol Chem 243:5921, 1968.

28. Freundlich M, Burns RO, Umbarger HE: Proc Natl Acad Sci USA 48:1804, 1962.

29. Umbarger HE: In Vogel HJ (ed): "Metabolic Pathways." New York:Academic Press, 1971, vol 5, p 447.

30. Morse DE, Guerlin M: J Mol Biol 63:605, 1972.

31. Quay SC, Dick TE, Oxender DL: J Bacteriol 129:1257, 1977.

32. Ovchinnikov YuA, Aldanova NA, Grinkevich VA, Arzamazova NM, Moroz IN, Nazimov IV: Bioorg Chem (Russian) 3:564, 1977.

33. Antonov VK, Alexandrov SL, Vorotyntseva TI: Adv Enzyme Regul 14:269, 1976.

34. Amanuma H, Itoh J, Anraku Y: J Biochem (Japan) 79:1167, 1976.

35. Low KB: Bacteriol Rev 36:587, 1972. 